\title{
LA INTERFERENCIA EN EJERCICIOS DE PRODUCCIÓN ORAL DE DOCENTES EN FORMACIÓN DE TERCER SEMESTRE DE INGLÉS COMO LENGUA EXTRANJERA \\ (ILE)
}

\author{
TRANSFER IN ORAL EXERCISES FROM THIRD SEMESTER \\ STUDENT-TEACHERS OF ENGLISH AS A FOREIGN \\ LANGUAGE (EFL)
}

\section{FRANCISCO ANTONIO PÉREZ-GÓMEZ* YEHICY ORDUZ NAVARRETE*}

\section{RESUMEN}

El siguiente estudio de carácter descriptivo-exploratorio se realizó con tres grupos de estudiantes de tercer semestre de una licenciatura colombiana en formación de docentes de lenguas extranjeras, durante seis meses. En dicho periodo se recolectó información de una muestra de audio en inglés como lengua extranjera y de dos encuestas realizadas luego de un trabajo teórico-práctico metalingüístico orientado por el docente de un curso de fonética y fonología. El objetivo del primer instrumento fue determinar los casos de interferencia de la lengua materna en la producción oral de los estudiantes de lengua extranjera; en cuanto al segundo instrumento, buscó explorar las percepciones que los aprendientes tuvieron ante el ejercicio teórico-contrastivo y de autoevaluación de su producción oral. Los resultados revelan que los estudiantes perciben que el sistema fonológico de la L2 dista mucho de aquel de su lengua materna, que ello ejerce interferencia en la producción oral generando errores de norma y de sistema y que, más allá de lo netamente lingüístico, hay fallas en los procesos de autorregulación.

Palabras-clave: Enseñanza de la pronunciación de ILE; Interferencia; Error y falta.

\section{ABSTRACT}

This descriptive-exploratory study was carried out within three groups of undergraduate students who were undertaking their third semester in a Colombian foreign languages teaching program over a six-month period. During this time, relevant information was collected from a recording sample in English as a foreign language and from two surveys, after a metalinguistic theoretical and practical work led by a teacher of a phonetics and phonology course. The aim in using the first instrument was to identify the transfer cases from mother tongue in the oral production of the foreign language students. The second instrument was intended to explore the perceptions that learners had on the theoretical

\footnotetext{
*Universidad Pedagógica Nacional, Bogotá (Cun), Colombia. fperez@pedagogica.edu.co

** Universidad Pedagógica Nacional, Bogotá (Cun), Colombia. yehicy_upn@yahoo.com
} 
and contrastive exercise and on their oral productions self-assessment. Results revealed that students perceived L2 phonological system as being far too different from that of their mother tongue; they also unveiled that this fact exerts interference over their oral production originating errors and that beyond the linguistic domain, there are mistakes in learners' self-regulation process.

Keywords: Teaching of pronunciation in EFL; Transfer; Error and mistake.

\section{INTRODUCCIÓN}

De antaño, la investigación en pedagogía de las lenguas extranjeras se ha encaminado principalmente en dos objetivos: uno, pedagógico, orientado a lograr el aprendizaje de parte del estudiante; y el otro, psicolingüístico, dirigido a explicar los procesos mentales inmiscuidos en ese logro. Tal interés ha generado metodologías, métodos y modelos, que han hecho que, tanto docentes como estudiantes, tengamos una visión panorámica de qué se hace, cómo se hace y por qué medio se hace.

Si revisamos qué se hace, los modelos cognitivos son los que más recientemente han hecho enormes aportes al intento de comprender cómo funciona la mente en el proceso de aprender a comunicar eficientemente en una lengua que no es la materna. Luego, si miramos cómo se hace, recordamos métodos como el Tradicional, el Directo, el Audio-oral, el Situacional, la Respuesta física total, la Sugestopedia, el Comunicativo o el Enfoque por tareas (MARTIN, 2009). Finalmente, si observamos por qué medio se hace, no nos alcanzarían estas páginas para enlistar la enorme cantidad de material representado en manuales y archivos de audio y video, sin contar con los millares de recursos que encontramos en la red.

Hay que mencionar además, que ambos campos (la pedagogía y la psicolingüística) han unido sus objetivos en trabajos interdisciplinarios que hoy buscan vencer las dificultades que puedan presentarse durante el proceso de aprendizaje. Una de ellas -que es mucho de nuestro interés-, relaciona el tema del error en la pronunciación. Y aunque en otras temáticas hay bastante por leer, es más bien moderado lo que se encuentra respecto a la descripción específica de los errores que, por influencia de la lengua materna (en adelante, LM), cometen los aprendices; igual sucede con la literatura que indica cómo aminorar su aparición en la producción oral.

Estos estudios se hacen relevantes por cuanto en la Universidad Pedagógica Nacional de Colombia, lugar de aplicación de nuestro estudio, trabajamos con docentes en formación, que no solo buscan la lengua extranjera para comunicar (deberán reconocer sus propios errores de pronunciación y entender por qué 
surgen y cómo aminorarlos) sino para enseñarla en diferentes ámbitos académicos (deberán saber manejar el error y ayudar a sus estudiantes a reducirlo).

En el presente artículo pretendemos hacer una aproximación analítica a la interferencia que la LM -español, ejerce sobre la producción oral de la lengua extranjera (en adelante, LE) -inglés. De igual manera, iremos más allá al fomentar, no solo una conciencia sobre el error en la pronunciación a partir de un ejercicio contrastivo, sino un ejercicio metalingüístico que evidencia una interlengua en proceso, y que será la base para el desempeño del futuro docente de inglés como lengua extranjera (en adelante, ILE) con sus propios estudiantes.

En este orden de ideas, nuestro esquema teórico revisará algunas temáticas que fundamentan el estudio, siempre, en torno a la pronunciación y al proceso de enseñanza/aprendizaje de ILE; además, basándonos en ejercicios prácticos realizados en aula de clase, presentaremos un análisis de algunos de los errores (consonánticos y vocálicos) producidos por los estudiantes de modo que sean fáciles de identificar y comprender. Enseguida, expondremos la metodología de investigación para luego mostrar el análisis de los datos obtenidos a partir de muestras lingüísticas y reflexiones generadas en los estudiantes luego de un ejercicio teórico-práctico. Terminaremos con unas breves sugerencias orientadas al docente de ILE y al docente en formación.

\section{ANTECEDENTES}

Varios autores han dado cuenta de los errores producidos por la interferencia de la LM de los aprendientes en la pronunciación de la lengua inglesa. Destacamos entre ellos el estudio de Bin-Hady (2017) con la interferencia del árabe al inglés; la investigación de Ohata (2004) sobre áreas segmentales y suprasegmentales que generarían problemas en la pronunciación del inglés para hablantes de japonés; el estudio realizado por Wheelock (2016) sobre las dificultades fonológicas que experimentó un grupo de aprendientes de inglés cuya LM es el italiano; y la investigación de Bayraktaroğlu (2008) con respecto a las dificultades de pronunciación en estudiantes turcos por la interferencia ortográfica entre su L1 y la lengua inglesa.

En lo concerniente al español encontramos estudios importantes: el de Guzmán y Martínez (2013) sobre la interferencia fonética del español al inglés en la producción de fonemas consonánticos de un grupo de estudiantes de una licenciatura colombiana en lenguas modernas; el que hizo Calvo (2013) sobre la enseñanza de la pronunciación del inglés en Galicia (Esp.) relacionado con las potenciales ventajas y 
dificultades que los estudiantes de bachillerato tendrían por ser hablantes bilingües (español-gallego); el estudio de Vioque (2015) donde explora la influencia del español y del inglés en la adquisición de la fonología de las consonantes oclusivas y africadas del alemán; el realizado por Catalán (2017) quien explora, desde la perspectiva de los docentes de inglés, los problemas que los estudiantes tienen al pronunciar en LE por influencia del español; finalmente, el estudio conducido por Canale (2012) quien da cuenta de los factores sociolingüísticos que inciden en la adquisición del fonema consonántico /v/ por parte de estudiantes universitarios uruguayos, al aprender inglés.

En estos estudios que nos han ayudado a despejar el camino, notamos que la tendencia es realizar un análisis contrastivo de errores producidos por adultos cuya LM interfiere en la pronunciación de la LE. Si bien a nivel local descubrimos un estudio con docentes en formación, éste adolece de un análisis detallado de la interlengua de los estudiantes y de una reflexión metacognitiva de las causas del error como está proyectado en el presente estudio.

\section{FUNDAMENTOS TEÓRICOS}

Para encuadrar de una mejor manera nuestro estudio, tendremos en cuenta seis aspectos importantes: la pronunciación en la enseñanza de LE -teniendo en cuenta el ¿́para qué?, y el ćcómo?, el periodo crítico en el aprendizaje de LE, la interferencia lingüística, la interlengua y el error, y los posibles errores de pronunciación en la producción de ILE por hispanófonos.

\subsection{Pronunciación y enseñanza de LE: ¿para qué?}

Muchos docentes alrededor del mundo han excluido, al menos parcialmente, de forma deliberada y consciente la enseñanza de la pronunciación en el aula de clase (BARTOLÍ, 2005; USÓ, 2008), y en contraposición, defienden el método comunicativo o el enfoque por tareas, como forma efectiva de lograr un aprendizaje que apunta a la competencia comunicativa. Una visión tal genera claramente una contradicción porque el hecho de comunicar requiere ser competente, no solo desde la lingüística, sino desde la pragmática: dos aspectos interconectados tanto en la escritura como en la oralidad.

Es por ello que, si tomamos el Marco Común Europeo de Referencia para la enseñanza de las lenguas extranjeras (en adelante, MCER), vemos dos cosas: una, que está orientado hacia la competencia comunicativa, y dos, que ésta se compone 
de otras que contienen la competencia fónica que incluye elementos segmentales y suprasegmentales. Encontramos pues en el MCER (2002):

La competencia fonológica supone el conocimiento y la destreza en la percepción y la producción de: las unidades de sonido (fonemas) de la lengua y su realización en contextos concretos (alófonos); los rasgos fonéticos que distinguen fonemas (rasgos distintivos; por ejemplo: sonoridad, nasalidad, oclusión, labialidad); la composición fonética de las palabras (estructura silábica, la secuencia acentual de las palabras, etc.); la fonética de las oraciones (prosodia) [que incluye] acento y ritmo de las oraciones (sic) y entonación; y la reducción fonética (p. 113114)

Como podemos observar, al excluir la pronunciación de las clases de LE, eliminamos, paradójicamente, un elemento fundamental de la competencia lingüística que es determinante en la competencia comunicativa. Es más, al centrarnos solo en la nimia tarea de hacernos entender, descuidamos, además de la propia lingüística, la formación socio-pragmática del hablante al dejar de lado elementos segmentales (de dicción) y suprasegmentales (de entonación) esenciales.

Si examinamos dicha problemática en el proceso de aprendizaje de ILE, nos llama la atención que la producción oral en esta lengua se caracteriza por dos fenómenos: la mutación de sonidos y la inadecuada entonación. Ambos generan cambios de significado, palabras inexistentes y disminución de la inteligibilidad del mensaje, que se acrecientan por falta de adecuación a la intención del enunciado. El aprendiente cae entonces en dificultades de orden pragmático y lingüístico que terminan, por ejemplo, en malos entendidos y trasgresión al principio de cooperación (GRICE, 1975) o al de relevancia (SPERBER y WILSON, 1986). Celce-Murcia et al. (1996), completan esta posición al mencionar:

[The] focus on language as communication brings renewed urgency to the teaching of pronunciation, since both empirical and anecdotal evidence indicates that there is a threshold level of pronunciation for nonnative speakers of English; if they fall below this threshold level, they will have oral communication problems no matter how excellent and extensive their control of English grammar and vocabulary might be (p. 7).

Ahora bien, orientando las anteriores reflexiones a la formación de maestros, queda claro que no es suficiente manejar un alto nivel de gramática y una competencia lexical avanzada si no se acompañan de habilidades de pronunciación y de una formación teórica. Esta última, orientada a los principios y fundamentos de la fonética y la fonología, da herramientas valiosas en los procesos de enseñanza y corrección. Llisterri (2003) no solo respalda esta afirmación sino que aconseja el ejercicio metalingüístico indicando: 
Así como nadie confiaría su salud a un médico que únicamente le prescribiera fármacos sin saber demasiado de la fisiología humana y de los motivos de las enfermedades, es lógico suponer que enseñar a pronunciar requiere no sólo poseer un conjunto de "recetas", sino también conocer la descripción fonética y fonológica de la lengua por una parte, y las causas de la interferencia fonética por otra (p. 109).

Allí precisamente radica la importancia de formar al futuro docente en este campo, así, no solo contribuirá a su propia formación lingüística sino que más adelante podrá replicarlo en aula de clase.

\subsection{Pronunciación y enseñanza de LE: ¿cómo?}

La enseñanza de la pronunciación de LE ha caminado en dos direcciones que, creemos, deberían ser complementarias. Una, tiene que ver con un proceso imitativo en el que el estudiante debe ser dueño de una enorme habilidad de escuchar y de imitar lo que escucha: sonidos, ritmo, duración y entonación; ello requiere también de grandes facultades para discernir qué es lo que se puede y no se puede imitar. La otra, de corte más formal, busca concientizar al aprendiz generando en él un proceso metalingüístico de análisis a través del uso de descripciones fisioarticulatorias, dibujos de cortes faciales, manejo del Alfabeto Fonético Internacional (en adelante, AFI), información explícita sobre el ritmo, la duración y la entonación, y ejercicios de imitación (CELCE-MURCIA ET AL., 1996).

Como dijimos, estas dos vías deberían conjugar una aproximación a la articulación de la LE y un acercamiento teórico que permita comprender las semejanzas y diferencias que hay entre la LM y la LE que se pretende abordar. Sería un ejercicio que no debe llevarse a cabo de manera independiente sino hacerse de forma constante, complementaria y cíclica, adecuándose a los hábitos de estudio y estilos de aprendizaje que impulsemos en nuestros docentes en formación. De este modo ellos comprenderán que pronunciar mejor no es sólo el resultado inmediato de estudiar teoría o de hacer ciertos ejercicios durante determinado semestre sino que resulta de la práctica permanente y reflexiva.

$\mathrm{Al}$ respecto Celce-Murcia et al. (1996) recomiendan una serie de ejercicios para practicar la pronunciación, entre ellos traemos a colación los siguientes: a) Escucha e imitación: ayudándose, no sólo del profesor titular sino de grabaciones, canciones, tutoriales, corpus orales, etc.; b) Entrenamiento fonético: estudiando los cortes faciales, el AFI (punto y modo de articulación), y la transcripción de muestras de habla reales; c) Pares mínimos: ejercitando la comprensión y producción oral de sonidos (en palabra o en frase) con cierto nivel de dificultad por su parecido con otros de la LE -pueden diferenciarse en un fonema o en la 
sílaba acentuada; d) Trabalenguas: entrenando la producción oral secuenciada de sonidos con cierta dificultad articulatoria; e) Lectura en voz alta: enfatizando en el acento, la pronunciación y la entonación, se puede involucrar un ejercicio memorístico; y f) Grabaciones: en audio o video, son útiles para la revisión, corrección y retroalimentación, no solo del profesor sino del estudiante mismo y de sus compañeros de clase.

Lo anterior se cimienta en el desafío que plantea el enseñar/aprender

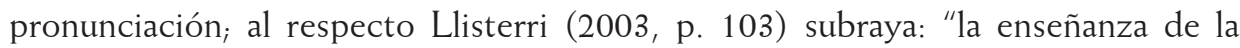
pronunciación se basa en una reeducación de la percepción para que el alumno llegue a asimilar adecuadamente las categorías fonéticas de la L2 y consiga, así, una producción lo más cercana posible a la nativa".

De otro lado y en complemento, Briz (2011) quien alude a Llisterri (2003), recomienda al profesor una serie de actividades que mejorarían su labor de enseñanza de la pronunciación: a) Definir los objetivos: en dos sentidos, el tipo de norma o variedad y el grado que se prevé obtener; b) Proyectar los posibles errores: a través del análisis contrastivo entre la LE y la LM del aprendiz; c) Estudiar la interlengua: con el objeto de complementar la proyección y delinear el tratamiento de los errores; d) Jerarquizar los errores: dependiendo de su tipología y de los objetivos comunicativos que se tracen; e) Revisar progresión: estableciendo el grado de logro de los objetivos trazados según sus niveles de dificultad; y f) Determinar el material: que puede incluir elaboración, revisión o adecuación según las necesidades específicas de los estudiantes.

\subsection{El periodo crítico en el aprendizaje de LE ¿obstáculo insalvable?}

Desde finales de la década de los sesenta cuando Lenneberg (1967) publicó The Biological Foundations of Language, ha habido amplios debates sobre las posibilidades que tienen, quienes dejaron la pubertad, de aprender una LE. El conocido período crítico, según el autor, hace que el aprendizaje dependa del grado de madurez cerebral pues se presenta en una etapa del desarrollo que finaliza junto con la lateralización y la plasticidad que caracterizan al cerebro infantil. Torres $(2005$, p. 2) insiste al respecto: "a medida que maduramos y la organización del cerebro se hace más especializada, nuestra capacidad para aprender un idioma tiende a decrecer"

Tal conclusión implicaría que nosotros como formadores de docentes en LE, tenemos un enorme reto que asumir: aquellos estudiantes que están en el proceso de aprender ILE tendrán más dificultades para adquirir las competencias fónicas, relacionadas con los fonemas, sus alófonos y la prosodia. Bien lo expone Torres (2005, p. 3) "la explicación más generalizada que reciben los errores de pronunciación del 
adulto es que unos órganos articulatorios que han estado produciendo un sistema fonológico durante años quedan de cierto modo 'atrofiados' para la producción de otro".

Esa atrofia genera variadas dificultades. Según algunos autores (KRASHEN, 2009; TORRES, 2005) y nuestra experiencia, ser adulto y estudiar una LE tiene varios contras originados en la biología misma del cerebro y/o en el contexto psicosocial del aprendiz. Desde el punto de vista biológico encontramos la disminución de la capacidad de asimilar un nuevo sistema debido a lo que se conoce como sordera fonológica (POLIVANOV, 1931). Para este autor, los aprendientes adultos están supeditados por el sistema fonológico de su propia lengua y se vuelven literalmente sordos al sistema fonológico de la LE. Más adelante Troubetzkoy (1987) retoma este concepto bajo el nombre de criba fonológica puntualizando que el sistema fonológico, al contener el conjunto de fonemas de la propia lengua, actúa como un filtro a través del cual se analizan los sonidos de la LE.

Desde el punto de vista psicosocial, vemos una timidez incrementada por el temor que genera gesticular un idioma ajeno y cometer errores frente a otros, la motivación (intrínseca o extrínseca), la presión social, el filtro afectivo y el ego lingüístico que adoptan los estudiantes cuando aprenden una L2. Este último se hace relevante porque, a medida de que nuestros aprendientes intentan emplear la $L E$, adquieren una nueva identidad y por su influjo adoptan una nueva forma de pensar, sentir y actuar (BROWN, 2007) que hace que se vuelvan más ansiosos e introvertidos. Vale la pena agregar un factor extra: la excesiva confianza en la forma escrita de la L2 pues se cree que refleja mejor la eficacia en los aprendizajes (TORRES, 2005).

En nuestros programas de formación de formadores encontramos también como contras: a) La presión del maestro de inglés para pronunciar mejor; b) El propio acento del maestro que puede constituirse en un elemento motivador o frustrante, si no se entiende o si no es de gusto de los estudiantes; c) El miedo a cometer errores o a ser corregidos en público; d) La timidez para repetir sonidos tanto en LM como en $\mathrm{LE}_{i}$ y e) El interés o falta de éste por mejorar la propia pronunciación.

Reflejo de todo lo expuesto es la actitud que nuestros docentes en formación adoptan con respecto a su proceso de aprendizaje, en este caso, hacia el desarrollo de habilidades de pronunciación. Hechos concretos de tal actitud se evidencian en la falta de autorregulación al hacer uso insuficiente de las herramientas virtuales y presenciales disponibles para mejorar la producción oral. Entre las más valiosas tenemos los tutoriales, softwares, bases de datos, corpus lingüísticos, blogs, páginas y plataformas educativas, además de las tutorías con el docente o los asistentes 
extranjeros, y ejercicios de autoaprendizaje. Sumado a lo anterior, tenemos el poco empleo de tiempo para el desarrollo de metas cognitivas planteadas desde la LE como son la discriminación auditiva de pares mínimos en ILE, la pronunciación de los pasados de los verbos regulares, o la reducción vocálica, entre otros.

Pese a lo anterior y sin perder de vista la población objeto de nuestro estudio, consideramos que la teoría del período crítico y todos sus contras, no pueden convertirse en un pretexto para que el maestro en formación no busque mejorar su producción oral; tampoco aceptamos que el formador de formadores deje de buscar los medios y estrategias que ayudarán a su estudiante a ejercitar aquellos aspectos que, la ya mencionada criba fonológica, dificulta.

Es por ello que entre los pros de ser un adulto que aprende una LE debemos tener en cuenta la experiencia que provee el potencial de aprender a aprender al conocer el propio estilo de aprendizaje, una mayor capacidad de concentración que facilita las actividades cognitivas y la facultad de autorregular el proceso de adquisición de la lengua determinando el ritmo del aprendizaje según la motivación (TORRES, 2005). Esto último va en consonancia con el concepto de inversión estratégica acuñado por Brown (2001), según el cual como docentes de LE, debemos insistir en que nuestros aprendientes jueguen un rol más activo y preponderante en su propio proceso. Un ejercicio tal supone una gran creatividad para proponer actividades eclécticas especialmente orientadas a los fines lingüísticos que trabajamos.

\subsection{La interferencia lingüística}

Antes de entrar en el tema conviene recordar que la interferencia o transferencia negativa -llamada así por la dificultad que los elementos de la L2 muestran al no estar presentes en la L1, es un fenómeno bien conocido. Su mención inicia a mediados del siglo pasado cuando Fries (1945) llama la atención precisamente sobre la influencia que la LM ejerce en el aprendizaje de una extranjera. Luego, a finales de los años 50, con el modelo del análisis contrastivo ${ }^{1}$, se planteó que la transferencia negativa era la causa principal de que los aprendientes de una segunda lengua cometieran errores gramaticales, lexicales y fonológicos. Después, para la década de los sesenta, la corriente iniciada por Chomsky $(1965,1968)$ y el cognitivismo, desligaría el carácter negativo de la interferencia y promovería que los errores cometidos por aprendientes de una lengua debían tomarse como un

1. Entendemos el Análisis contrastivo según Lleó (1997) como un modelo que busca predecir las dificultades en el aprendizaje de una LE a partir de la comparación de los sistemas fonológicos de las lenguas involucradas. De ello resultan elementos similares, fáciles de aprender (transferencia positiva), o elementos diferentes, difíciles de aprender (transferencia negativa)." 
proceso mediante el cual los estudiantes construyen significado creativamente, siendo entonces, una competencia en evolución; de ahí en más Selinker (1969) inicia sus referencias al proceso de interlengua. Finalmente, desde los años 80 hasta la actualidad renace el interés por estudiar el fenómeno según nuevas perspectivas en las que la lengua no se aprende sino que se adquiere y es empleada por sujetos interculturales. Estos, aun con errores, pueden usar una lengua franca cuyo objetivo primordial sería la comunicación. Aquí vale la pena aclarar que en nuestro contexto de formadores de formadores la enseñanza-aprendizaje sobrepasa la flexibilidad de esta variedad, buscando siempre un inglés estandarizado.

Ahora bien, entendiendo hoy la interferencia lingüística desde la perspectiva de Wang (2009), vemos que se constituye como un proceso en el que los aprendientes realizan generalizaciones desde su conocimiento de la LM para ayudarse en el aprendizaje de otra lengua. Siendo así, la transferencia se puede entender como una estrategia metacognitiva más que nuestros estudiantes emplean para aprender una LE, por tanto, no sería un fenómeno necesariamente negativo e insalvable.

En añadidura está el asunto de la escritura que incluimos aquí porque, para el caso de la contrastación entre las lenguas que estamos abordando, es un ingrediente primordial para la generación de errores en la pronunciación. La causa es que, siendo el español una lengua más fonética que el inglés, su escritura da pistas falsas sobre la pronunciación, afectándola de manera ostensible (DELATTRE, 1945). En complemento, Lado (1958) alude a esta dificultad cuando describe las dos posibles causas de errores en la pronunciación:

One possibility is that the same symbol might represent two different sounds in the two languages. In such a case the student tends to transfer the native language symbolization to the foreign language... The other possibility of spelling interference with pronunciation arises with inconsistencies in the spelling of the foreign language. The symbol which in one word represents the one sound turns out to represent a different sound in another word. The student mispronounces the word by assuming that the symbol represents the same sound in both cases (p. 20).

\subsection{La interlengua y el error}

Hemos mencionado varias veces la interlengua sin dejar clara la concepción que trabajamos. Siempre basados en Selinker (1969) y en Santos Gargallo (1993), compartimos la sinopsis que menciona Orduz (2012) al definirla como:

Un sistema lingüístico no-convencional propio de los aprendices de idiomas extranjeros, empleado en un esfuerzo por utilizar la nueva lengua; se caracteriza por ser autónomo e 
internamente estructurado y establece en su variabilidad, la posibilidad de ser descrito mediante un subconjunto de reglas de la gramática de la lengua objeto (p. 93).

En otras palabras, la interlengua es un sistema transitorio e independiente que se caracteriza por su inestabilidad, simplificación y sobregeneralización. Esas peculiaridades hacen que en las producciones (ya sea orales o escritas) se genere gran cantidad de errores que el docente tiende a relegar por razones de tiempo, al dar prelación a los aspectos léxico-gramaticales. Finalmente, es bueno mencionar que la interlengua puede incluir, según Santos Gargallo (1993), una detención inconsciente y permanente de la aproximación hacia la L2, produciendo lo que se conoce como fosilización.

Teniendo presente lo anterior, entramos entonces en la cuestión del error, al que debemos distinguir de la falta; el primero incluye contravenciones a las reglas del sistema y la segunda, lapsus de producción. Lee (2012) lo clasifica y aclara así:

D'une manière générale, quant au classement des types d'erreurs commises par l'apprenant de langue étrangère, trois types d'écarts sont envisageables ; 1) écart lié à la parole, qualifié de lapsus ou de ratés, plus largement de faute, 2) écart par rapport à la norme, qui fait l'objet d'une correction dans la grammaire ..., c'est-à-dire, qui se considère comme erreur, 3) écart par rapport au système de la langue, renvoyant aux énoncés « hors système » (p. 12).

Como vemos, el autor refiere tipologías que tienen que ver con el habla, la norma y el sistema, en donde la falta apuntaría a la primera, y el error, a los dos siguientes. Somos conscientes de que todo hablante, nativo y extranjero, comete faltas de orden lingüístico e incluso pragmático, por ello, nuestro interés se orienta hacia el error, en especial, el de pronunciación que afecta la comunicación por generar problemas de significación. Algunos ejemplos que encontramos en la producción oral de nuestros estudiantes son:

Tabla 1. Ejemplos que ilustran la diferencia entre falta y error según Lee (2012).

\begin{tabular}{|c|c|c|c|}
\hline & Frase & $\begin{array}{l}\text { Transcripción de la } \\
\text { producción oral }\end{array}$ & $\begin{array}{l}\text { Transcripción de la forma } \\
\text { del sistema }\end{array}$ \\
\hline Falta & I like eating crisps & *[aI lark 'i:tın k.IIsp] & /ar lark i:tın kıIIsps/ \\
\hline Error de norma & Come to my house & $*$ [kam tu mi: aus] & /kım tə mai havs/ \\
\hline Error de sistema & To be honest. & *[tu bi: 'hanəst] & /to bi: 'anəst/ \\
\hline
\end{tabular}

$\mathrm{Al}$ concatenar los dos términos que dan título a este apartado vemos que la interlengua es un peldaño obligatorio que todo estudiante debe andar en el camino al aprendizaje y, por sus características y definición, es un terreno abundante en errores, no solo lingüísticos sino pragmáticos. Burkhardt (2004, p. 11) afirma al 
respecto: "les erreurs sont ici conçues comme le reflet du processus d'apprentissage, en ce qu'elles sont la manifestation d'une hypothèse fausse faite par l'apprenant sur la langue, mais juste en regard de son propre système".

Aclaramos que, precisamente por formar parte de la interlengua, no consideramos que el error sea un obstáculo sino más bien una oportunidad en el sentido de que, al ser conscientes de lo progresivo del proceso y de las dificultades que se presentan en el camino, podemos establecer estrategias y planear ejercicios que contribuyan a su disminución. Es así, que cuando el autor habla de una hipótesis, deja implícito el trabajo del docente: corregir y ejercitar para que la interlengua continúe en su camino hacia la lengua objeto. Pero, si ello no sucediese, el peligro más grave sería la ya mencionada fosilización que Burkhard (2004) también refiere:

Corriger les erreurs devient positif pour l'apprentissage d'une L2 car le feed-back est un moyen pour l'apprenant d'infirmier ou de confirmer ses hypothèses et donc de faire évoluer son interlangue. C'est donc en partie par l'erreur qu'on apprend, en réglant progressivement son système sur celui de la langue-cible. Dans cette optique, on court le risque, si on ne corrige pas l'erreur, d'une fossilisation de l'interlangue, c'est-à-dire d'une fixation de règles imparfaites dans le système de l'apprenant (p. 11).

Según lo expuesto, es claro que, dejar pasar el error, puede convertirse en una falla grave de enseñanza-aprendizaje por cuanto éste puede fijarse en la mente del aprendiente. Esa razón es la que nos exhorta, como docentes de docentes en formación, a observar con detalle y a hacer un análisis minucioso de los errores de pronunciación en la producción oral de ILE.

\subsection{Posibles errores de pronunciación en la producción oral de ILE por estudiantes hispanófonos}

Este apartado resulta de la observación y sistematización rigurosa de muestras lingüísticas producidas por docentes en formación durante los últimos cinco años, lo que nos permite describir la causa de los errores más frecuentes. La metodología empleada para el análisis tiene en cuenta las sugerencias de Corder (1967), que apuntan a identificar los errores en su contexto (ejercicios en clase de L2 de docentes en formación), hacer su clasificación y descripción, explicar su posible origen o causa, y en nuestro caso particular, ir más allá dando cuenta de los casos de interferencia que se presentan en el proceso de interlengua.

Puntualmente, el análisis que mostramos enseguida surge del contraste entre los segmentos consonánticos y vocálicos del inglés y del español pero no debe tomarse como una generalización aplicable a todos los hablantes hispanófonos sino como un corpus digno de ser tenido en cuenta como base para otros hallazgos. 
2.6.1. Consonantes: Para describir en detalle las consonantes, es importante recordar conceptos claves como punto de articulación (zona de la cavidad oral en la que se produce el sonido), modo de articulación (forma en la que el aire sale del tracto vocal), sonoridad (participación de los pliegues vocales) y par mínimo (pareja léxica cuyos componentes se oponen entre sí por un segmento). También, debemos tener en cuenta los tres posibles contextos o posiciones en los que se presentan: inicial (al principio de la palabra), media o intermedia (en medio de vocales dentro de la palabra) y final (al finalizar la palabra).

a) Oclusivas: en su producción hay un cierre total de la cavidad oral que obstruye la corriente de aire, seguido de una apertura que libera la presión con una explosión. A simple vista parece no haber dificultades en la producción de estos segmentos, sin embargo, debemos tener claro que en la interlengua de los aprendientes se podrían encontrar algunos errores usando /t/ y /d/, ya que en inglés tienen punto de articulación alveolar y no dental como en español. Además, en inglés la producción de las oclusivas sordas va acompañada de una aspiración que las hace sonar diferente a las del español, lo que genera inevitablemente errores de norma. En cuanto a las sonoras bilabial y velar /b//g/, no habría interferencia puesto que su articulación es equivalente de una lengua a otra. Algunos ejemplos de la confusión que mencionamos está en: ten *[ten] $\sim / \mathrm{t}^{\mathrm{h}} \varepsilon \mathrm{n} /$, Dan $*\left[\right.$ dan] $\sim / \mathrm{d} n /$, camp $*\left[\right.$ 'kamp] $\sim / \mathrm{k}^{\mathrm{h}}$ æmp/, peel *[pil] $\sim /$ $\mathrm{p}^{\mathrm{h}} \mathrm{i}: \mathrm{i} /$.

Vale aclarar que, si bien el cambio de punto de articulación o la ausencia de aspiración no afectan seriamente la comunicación al momento de pronunciar, sí es muy importante que nuestros estudiantes de licenciatura los produzcan de manera apropiada porque no solo serán comunicadores y usuarios sino ante todo, modelos lingüísticos para sus estudiantes.

b) Nasales: son consonantes que se producen cuando hay un cierre de la cavidad oral, pero, el velo del paladar queda abierto, y el aire puede pasar a través de la cavidad nasal. Tanto en inglés como en español existen las nasales $/ \mathrm{m} / \mathrm{y} / \mathrm{n} /$ que no presentan inconvenientes pero además, en inglés es muy común la velar $/ \mathrm{y} /$ que algunos estudiantes tienden a pronunciar como /n/. Esta confusión genera buena cantidad de errores en la interlengua, así, en lugar de decir thing / $\theta \mathrm{ry} /$

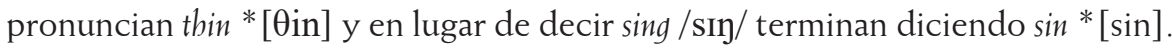


Subrayamos pues que la falta de distinción entre las nasales $/ \mathrm{n} /$ y $/ \mathrm{y} /$ sí genera problemas de comprensión al hacer cambiar el significado de la palabra ${ }^{2}$.

c) Fricativas: se producen cuando hay un estrechamiento ocasionado por la aproximación de dos órganos articulatorios, originando una modificación de la corriente de aire que genera una fricción con turbulencia. Las fricativas en español latinoamericano son: $/ \mathrm{f} / \mathrm{/} / \mathrm{s} / \mathrm{/} / \mathrm{j} / \mathrm{y} / \mathrm{x} /{ }^{3}$ mientras que en inglés existe un mayor número: $/ \mathrm{f} /, / \mathrm{v} /, / \theta /, / \mathrm{d} /, / \mathrm{s} /, / \mathrm{z} /, / \mathrm{J} /, / \mathrm{z} / \mathrm{y} / \mathrm{h} /$. Como quiera que los hispanohablantes presentan diversos problemas en torno a las fricativas inglesas, nos referiremos a los más relevantes y persistentes en la interlengua.

- /f/-/v/: claramente nuestros estudiantes no tienen dificultades para pronunciar la /f/, el error surge cuando deben contrastar pares mínimos comofan/van, off/of, ferry/very. El problema radica en la tendencia a pronunciar con bilabial [b] todas las palabras que contienen $/ \mathrm{v} /$ en posición inicial o intermedia, o [f] cuando /v/ está posición final. Así, la palabra van suena *[ban] /væn/, vowel suena *['bauel] /vavəl/ y very *['beri] /'ve..ii/; y para el segundo caso, en vez de producir of producen ${ }^{*}[\mathrm{of}] \sim / \mathrm{pv} /-/ \partial \mathrm{v} /$.

- /s/-/z/: se presenta un caso similar al anterior. Al no tener el español la $/ z /$, nuestros aprendientes tienden a pronunciar la sorda /s/ en todos los contextos sin tener en cuenta que el inglés incluye la sonora en su inventario fonológico. Por este fenómeno se producen errores serios en la interlengua, que generan fallas de comunicación pues no diferencian palabras como ice/eyes ofase/phase. Este mismo problema se ve reflejado en el hecho de que no emplean $/ z$ / al pronunciar la tercera persona de los verbos ni los plurales pues para ellos las palabras cuts/grabs se pronunciarían * [kats] - * [grabs] y no $/ \mathrm{k}^{\mathrm{h}} \Lambda \mathrm{tz} /$ - /g.æabz/, y los plurales cats/dogs lo pronuncian con interferencia evidente en ${ }^{*}[\mathrm{kats}]$ - *[dogs] en lugar de $/ \mathrm{k}^{\mathrm{h}} æ t \mathrm{ts} /$ - /dagz/.

- $\quad / \theta /-/ \partial /:$ como ninguna de las dos existe en español, este par de consonantes representa, a nuestro juicio, el segundo en grado de dificultad después de la aproximante-retrofleja /.t. Particularmente, los estudiantes tienden

2. Aclaramos que en algunos dialectos británicos y del sur de Estados Unidos, la confusión de estos dos sonidos es una práctica común ente hablantes nativos. No obstante, en el inglés estandarizado sí se hace la debida distinción y por tanto el futuro docente deberá apropiársela.

3. Es importante también tener en cuenta que en el español hispanoamericano encontramos muy frecuentemente la glotal fricativa sorda $/ \mathrm{h} /$, que particularmente pertenece a nuestro español colombiano. 
a pronunciar la fricativa-dental-sorda $/ \theta /$ en algunos casos como $/ \mathrm{t} /$, por ejemplo *[tink] o como /f/ en *[fing], en lugar de think / $\theta$ ink/; y en casos aislados, producen $/ \mathrm{s} / \mathrm{como}$ en thank you *['scnkju]. Con respecto al fonema $/ \delta /$, nuestros aprendientes tienden a pronunciarla como una $/ \mathrm{d} /$, así, pares mínimos como they/day sonarán como *[dei] /ðeI/ - /deI/; lo mismo sucede con then/den, though/dough. En otros casos, los estudiantes no identifican la diferencia entre $/ \theta /-/ \delta /$, ya que tienden a emplear en la interlengua solamente la primera y no tanto la segunda, de tal manera que cloth - clothes suenan *[klo $\theta]$ en lugar de $/ \mathrm{kla} \theta /$ - /kləoðz/.

- $\quad / \int /-/ 3 /$ : la dificultad para producir la consonante / $/$ / radica en la confusión que genera con la africada-palatal-sorda $/ \mathfrak{t} /$ (que referiremos en el siguiente grupo consonántico), aunque en español la empleemos en palabras como sushi, goulash o show e interjecciones como ish! De otro lado está la sustitución que realizan con $/ 3 /$, que no existe en el inventario fonológico de nuestra lengua, y es de origen francés. Al no tener una referencia en LM, los estudiantes provocan un error en la interlengua al pronunciar $/ 3 / \mathrm{como} /$ $\int /$; por ejemplo, television se escucha *[tele' $\left.\beta \mathrm{i} \int \mathrm{\int on}\right] \sim /$ 'teləvizən/. Lo mismo sucede con palabras como casual, usual, occasion.

d) Africadas: son consonantes que inician con una oclusión de los órganos articulatorios, seguida de una fricción rápida. En el caso del inglés existen dos consonantes africadas, la / $\mathfrak{g} /$ como en chat, coach y catchy, y la $/ \mathrm{d} z /$ como en june, judge y cages, pero con diferente sonoridad: la primera sorda, la segunda, sonora. Al contrario, en español solo tenemos la sorda $/ \mathfrak{t} /$ pues $/ \mathrm{d} z /$ no pertenece al inventario fonológico. Esta última se substituye de varias maneras en la interlengua: cuando va en posición final, como $/ \mathfrak{t} /$ en el caso de advantage, * [ad'bantatf], y en posición media, como/j/en el caso de agile *[a'jil].

En este mismo grupo es curioso encontrar en nuestros estudiantes, la dificultad para pronunciar la $/ \mathrm{g} /$ pues, aunque existe en nuestra lengua, la sustituyen por /S/en la pronunciación de chip, cheep y choose que suenan más bien como ship, sheep

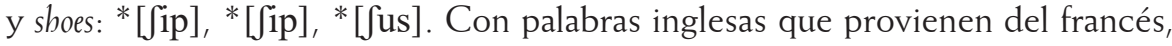
paradójicamente sucede el fenómeno contrario, una ultracorrección que hace que en la interlengua obtengan la pronunciación de charade y champagne con / t /, mas no con $/ \mathrm{J} /$. 
e) Aproximantes: se producen por medio del acercamiento de dos órganos de articulación sin que haya interrupción o constricción de la corriente de aire -como sí sucede con las oclusivas o las fricativas. En la lengua inglesa, la consonante aproximante por esencia es / I/ y nuestros estudiantes presentan grandes problemas al intentar pronunciarla, quizá por la dificultad articulatoria: postalveolar-aproximante-sonora. El español no tiene correspondencia por lo que los aprendientes la reemplazan en la interlengua por la alveolar-vibrante simple-sonora / $\mathrm{r} /$, o incluso por la alveolar-vibrante múltiple-sonora $/ \mathrm{r} /$, que no pertenecen al inventario fonológico de la lengua inglesa. Es así que en las palabras red, carrot, teacher producen errores de pronunciación respectivamente como $*\left[\mathrm{re}^{\gamma}\right],{ }^{*}\left[{ }^{\prime}\right.$ karot $], *[$ 'titfer $]$.

Otro obstáculo que encuentran nuestros estudiantes con respecto a esta consonante tiene que ver con el fenómeno de la no roticidad, es decir, con la omisión de la / $\mathbf{x} /$ en contextos intervocálicos y finales, típico del inglés británico y australiano. Los estudiantes tienen dificultades tanto para reconocer fonológicamente palabras cuando se pronuncian sin roticidad (p.ej., car park, /

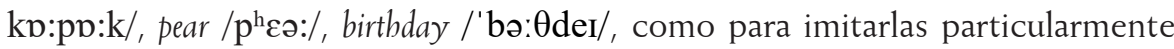
con un acento británico. Esto los hace lucir incómodos y su pronunciación suena bastante artificial. De otro lado, es bueno advertir que, cuando se presenta no roticidad en una palabra, se compensa con un alargamiento de la vocal pero en muchas ocasiones, los estudiantes no lo tienen presente y olvidan hacerlo. Así, el error en la interlengua suena: *[kar' par], *[pear], * ['berdei].

Si bien este tipo de pronunciación no afecta directamente la comprensión, la falta de corrección del error hace que nuestros futuros docentes de inglés se queden en su zona de comodidad y rehúyan los ejercicios de corrección. El problema grave es que pueden difundirlo entre sus estudiantes.

f) Semiconsonantes: $[\mathrm{j}]-[\mathrm{w}]$, que se conoce en lengua inglesa como semivowels o glides, en español se presentan solo como alófonos de las vocales /i/ - /u/ respectivamente. La cercanía con la legua materna crea la tendencia a aplicar sus procesos evolutivos en la producción oral de ILE. Es el caso de [j], en donde se presenta un proceso de consonantización, es decir, los estudiantes la convierten en una consonante y pronuncian las palabras yes - yellow - you como ${ }^{*}[$ dzes $] \sim$ /jes/, *[dzelou] $\sim /$ jelov/, ${ }^{*}[$ dzju] $\sim$ /ju:/. Con respecto $[w]$, es interesante observar que los futuros docentes hacen una prótesis de 
velar al anteponer una velar-oclusiva-sonora $/ \mathrm{g} /$ como sucede con weak - well que pronuncian erróneamente en inglés como * ['gwik] y * [gwel]

2.6.2. Vocales: Para el estudio de las vocales tendremos en cuenta a Quilis (1993) quien propone el movimiento de dos órganos articulatorios: labios y lengua. Los primeros se abordarán en dos rasgos: redondeado y no redondeado (aunque para este último especificaremos fuerte -más retraído- y relajado -menos retraído). Y para la lengua se tendrán en cuenta los movimientos en horizontal (anterior-central-posterior) y en vertical (alto-medio-bajo). Aparte de lo anterior, consideramos relevante hacer referencia al movimiento mandibular que genera rasgos relacionados con apertura y cierre (abiertosemiabierto-semicerrado-cerrado). Asimismo, agregamos en la descripción el fenómeno del alargamiento que afecta la duración del segmento vocálico correspondiente.

a) $/ \mathbf{a} /$ sustituye $/ \mathfrak{a} /, / \mathbf{a} /, / \mathbf{a}: /, / \mathbf{I} /, / \mathbf{o} /$. El hábito de pronunciar una vocal central-bajaabierta-no redondeada genera en la interlengua, una dificultad al posicionar la lengua por fuera del rango adquirido en su L1. Para el caso de /æ/ encontramos que muchos aprendientes no perciben auditivamente la diferencia que genera la posición lingual, un poco más adelantada y alta, y tampoco la leve reducción de la apertura mandibular; es el caso de man *[man] /mæn/.También está la interferencia que se presenta con schwa / $/$ / que tiende a producirse como abierta en sílabas átonas como en about * [a'baut] /o'bavth/. Para la /a/ (típica del inglés americano), encontramos dificultades en el movimiento lingual hacia la zona posterior de la cavidad oral y una limitación de limitan la apertura que la caracteriza en inglés; aunque no es radicalmente problemático, tenemos como ejemplo palm *[palm] /pam/. Luego, con la /a:/ (presente en el inglés británico), a la dificultad del movimiento lingual se suma la duración, por ejemplo father *['faðer] /fa:ðə/. Al final tenemos la /I/, cuyo error se genera por la pista falsa que da la escritura, así, en la palabra village, hay una $<a>$ que genera una producción *['bilaf], en lugar de /'vilidz/.

b) $/$ e/ sustituye $/ \boldsymbol{\varepsilon} /, / \mathbf{\jmath} /$, $/ \mathfrak{x} /$. Debido a la presencia de una única vocal anteriormedia- semiabierta-no redondeada, la dificultad para producir vocales más abiertas, bajas y centrales se hace mayor y genera fallas en la interlengua. A este respecto, la $/ \boldsymbol{\varepsilon} /$, cuya diferencia radica en una posición lingual guiada por un leve descenso en la mandíbula, genera dificultad al producir palabras como bed *[beð] $\sim /$ bed/ o sell *[sel] /scl/; aclaramos que no es un error irreconciliable en la comunicación pero insistimos, que es esencial eliminarlo en la producción 
oral de un docente de ILE. En cuanto a la schwa /ə/, la dificultad subyace en el movimiento lingual y labial, puesto que ésta se ubica en la parte central de la cavidad oral y no exige movimiento labial. De otro lado, la forma escrita de la palabra le da pistas erróneas al aprendiente logrando que produzca una vocal fuerte en lugar de una débil que, muy frecuentemente, puede ser absorbida por las consonantes del contexto. Tenemos como ejemplo: garden *['garðen] / 'ga:dən/ - /'ga:dn/4. Para el caso de la /æ/, la dificultad radica en un descenso lingual que debe estar acompañado de una ligera apertura mandibular. Un ejemplo es thanks $*[\theta$ enks $] \sim / \theta æ y k s /$.

Finalmente, hay un fenómeno muy común en nativos de español: una prótesis que incluye el segmento vocálico /e/ al iniciar cualquier palabra que contenga combinación consonántica $s+$ cons; ejemplos de ello son small *[es'mol], street *[es'trit], speak * [es' pik].

c) $/ \mathbf{i} /$ sustituye $/ \mathbf{I} /, / \mathbf{o} /, / \mathbf{i}: /$. La presencia en español de la vocal anterior-altacerrada-no redondeada influye en la producción de otras con características aproximadas y con movimientos linguales un poco más bajos y largos, además de la relajación del movimiento labial que presenta la lengua inglesa. En lo concerniente a /I/ el movimiento lingual descendente y una tenue reducción de la tensión labial provocan una dificultad articulatoria que el aprendiente prefiere eludir. Encontramos un ejemplo en: it $*[i t] \sim /$ It $/$. En cuanto a schwa, el error de norma proviene de las características arriba mencionadas, agregando la información visual equívoca de la escritura, que conlleva la producción de un elemento más cerrado. Así, pencil suena *['pensil] /'pensəl/. Respecto a la /i:/, la pérdida de la duración es la que realmente influye y genera errores en el sistema pues, cuando los aprendientes pronuncian, por ejemplo, *[mil], no entendemos si refieren /mil/ o / mi:1/. La única forma de desambiguar esta anomalía léxica es prestando atención al contexto en el que intentan emplear la palabra y así descartar una de las dos posibilidades.

d) $/ \mathbf{o} /$ sustituye $/ \mathbf{o}: /, / \mathbf{s} /, / \mathbf{\partial} /, / \mathbf{w} /$. El hecho que en español exista la vocal posteriormedia-semiabierta-redondeada tiene una gran incidencia en que los aprendientes produzcan en la interlengua sonidos de naturaleza similar, pero alargados, más centrales y con un mayor grado de apertura de la cavidad oral. Con relación a /o:/, la distinción se presenta básicamente por la duración que produce una leve tensión en los labios. Un ejemplo es la pronunciación de *[bol] $\sim$ /bo:1/.

4. La absorción de la /ə/, implica la formación de una consonante silábica. 
En cuanto a $/ \Lambda /$ el error de norma se presenta por tres rasgos principales: la apertura de la cavidad oral, la relajación labial y el desplazamiento lingual hacia una posición media. Observamos lo anterior en ugly * ['ogli] /' glis/. Para el caso particular de la schwa tenemos diferencias en posición lingual, mandibular y labial ya que la lengua desciende y se centra, la mandíbula se abre ligeramente y los labios se relajan. Sumado a ello, la presencia de la forma gráfica de la $<0>$ guía una producción más cerrada y redondeada. Este fenómeno se ilustra con lemon *['lemon] /'lemən/. Por último la vocal /p/ (propia del inglés británico) sufre una sustitución básicamente originada por la poca apertura mandibular. Un ejemplo se presenta en la producción de bot * [hot] $\sim / \mathrm{hpt} /$.

e) $/ \mathbf{u} /$ sustituye $/ \mathbf{u}: /, / \boldsymbol{\sigma} /, / \mathbf{N} /$. La existencia de la vocal posterior-alta-cerradaredondeada afecta la duración y apertura de los segmentos que sustituye. En el caso de la /u:/ solo se influye la duración, sin embargo el error no solo afecta el significado sino la posibilidad de generar una anomalía léxica. Tenemos como ejemplo la palabra pool $*$ [pul] $\sim / \mathbf{p}^{\mathrm{h}} \mathbf{u}: \mathbf{l} /$ que a nuestro oído se confunde con $\mathrm{pull} / \mathrm{p}^{\mathrm{h}} \mathrm{\mho l} /$. Hablando del sonido/ / / la dificultad para los aprendientes es el leve descenso lingual que obliga su producción, una muestra de ello está en good * [guð] $\sim / \mathrm{g} v \mathrm{~d} /$. Con respecto a $/ \Lambda /$ la sustitución se presenta por una mayor apertura mandibular, un descenso lingual y la relajación de los labios, como sucede en cut $*\left[\mathrm{kutt}_{n}\right] \sim / \mathrm{k}^{\mathrm{h}} \Lambda \mathrm{t} /$. Por último encontramos la interferencia que se presenta cuando los aprendientes relacionan la forma escrita de $<\mathrm{u}>$ con la pronunciación de la vocal española, por ejemplo *['guanderfull]/ /'wındəəfəl/.

f) $/ \mathbf{\gamma} /-/ \mathbf{a} / \mathbf{v s .} / 3 /-/ \mathbf{3} /$. Incluimos esta distinción por ser relevante al causar confusión en nuestros estudiantes. Existen dos causas que los conducen al error: una tiene que ver con el desconocimiento de la acentuación en ILE puesto que / a / se presenta en posiciones átonas y $/ 3 \%$ se presenta en sílabas tónicas. Por otro lado está el grado de apertura mandibular que es mayor para la segunda y genera enorme dificultad pues en español no hay ningún sonido que se le asemeje. Un ejemplo que expone el conjunto es furniture *[fəni'tøa] - *['fernitfur] $\sim$

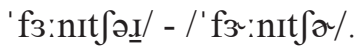

\section{ANÁLISIS TEÓRICO}

En el análisis de datos de este estudio cuantitativo-cualitativo de gran escala (54 muestras lingüísticas) se empleó como metodología la teoría fundamentada de 
los datos y sus respectivas etapas propuestas por Freeman (1998). En coherencia codificamos la gran cantidad de datos recolectados asignándoles nombres o etiquetas, luego hicimos la respectiva agrupación en categorías que no estaban preconcebidas sino que emergieron de los datos mismos, en seguida procedimos a encontrar relaciones en tales categorías, luego determinamos un orden jerárquico de para mostrar al final, los resultados obtenidos.

La recolección sistemática de datos se fundó en diversos instrumentos de investigación, entre los que están los diarios de campo de los dos investigadores, las reflexiones surgidas a partir de su puesta en común, las muestras lingüísticas ${ }^{5}$ tomadas por los investigadores durante los cursos de fonética, y las encuestas respondidas por la población participante en este estudio.

Buscando una mayor organización y practicidad, dividiremos nuestro análisis en dos apartados: en primer lugar mostraremos los errores más relevantes y frecuentes que nuestros estudiantes produjeron a nivel comunicativo en la muestra inicial, y en segundo lugar daremos a conocer los resultados obtenidos de la encuesta aplicada a toda la población, posterior a las grabaciones.

\subsection{Descripción de los errores de mayor relevancia y frecuencia}

3.1.1. Consonantes: La tabla inferior muestra el inventario fonológico de ILE en donde ensombrecimos los elementos que, a partir del análisis, generaron mayor número de errores por la interferencia con el español. La mayoría de ellos surgió de dos fenómenos: el primero implica la inexistencia del sonido en el inventario fonológico de la LM de los aprendientes; el segundo involucra la ausencia, en español, del contorno fonético/ fonológico que requiere ILE. Al revisarlos en conjunto, surgió el análisis que exponemos enseguida.

5. Surgieron de un ejercicio práctico-investigativo propuesto a los estudiantes en donde debían elaborar una cartilla de pronunciación de la lengua inglesa. En ella hubo 4 etapas: la primera, relaciona una grabación de lectura de texto narrativo que tanto docente como estudiantes tenían como muestra inicial de su producción oral. Luego, debieron investigar acerca del inventario fonológico de la lengua inglesa y producir oralmente y grabar una serie de palabras que ejemplificaran cada uno de los fonemas encontrados. Al final, debieron hacer de nuevo la misma lectura aplicando en la producción oral la corrección fonética según lo estudiado. 
Tabla 2. Cuadro consonántico de ILE que señala los segmentos con mayor interferencia.

\begin{tabular}{|c|c|c|c|c|c|c|c|c|c|c|c|c|c|c|c|c|}
\hline \multirow[t]{2}{*}{ Lugar } & \multicolumn{2}{|c|}{ bilab } & \multicolumn{2}{|c|}{ labiode } & \multicolumn{2}{|c|}{ dent } & \multicolumn{2}{|c|}{ alveol } & \multicolumn{2}{|c|}{ posalve } & \multicolumn{2}{|c|}{ palat } & \multicolumn{2}{|c|}{ velar } & \multicolumn{2}{|c|}{ glot } \\
\hline & - & + & - & + & - & + & - & + & - & + & - & + & - & + & - & + \\
\hline Oclusiva & $\mathrm{p}$ & $\mathrm{b}$ & & & & & $\mathrm{t}$ & $\mathrm{d}$ & & & & & $\mathrm{k}$ & $\mathrm{g}$ & & \\
\hline Africada & & & & & & & & & & & t & ds & & & & \\
\hline Fricativa & & & $\mathrm{f}$ & $\mathrm{v}$ & $\theta$ & ð & $\mathrm{s}$ & $\mathrm{z}$ & $\int$ & 3 & & & & & $\mathrm{~h}$ & \\
\hline Aproximante & & & & & & & & & & I & & & & & & \\
\hline Lateral & & & & & & & & 1 & & & & & & & & \\
\hline Nasal & & $\mathrm{m}$ & & & & & & $\mathrm{n}$ & & & & & & $\eta$ & & \\
\hline
\end{tabular}

En el caso de las oclusivas bilabial, alveolar y velar sordas, cuya pronunciación exige la aspiración en los tres contextos de aparición, y para las sonoras, cuya dificultad reside en los contextos de posición final, la afectación está dada por el segundo fenómeno antes mencionado.

En lo que concierne a las consonantes fricativas fue importante descubrir que se constituyeron en la fuente principal de los errores de pronunciación ya que encontramos que los dos fenómenos arriba señalados se presentan de manera recurrente. El caso particular fue el que se dio con la glotal-fricativa-sorda, cuya dificultad radica en la confusión que la grafía $\langle\mathrm{h}\rangle$ genera en los aprendientes puesto que, dependiendo del origen etimológico de la palabra, se determina la presencia o no de la consonante $/ \mathrm{h} /$ en ella.

Respecto a las consonantes africadas, la dificultad primordial estuvo en el primer fenómeno ya mencionado para la sonora, y para la sorda, la confusión con otros sonidos de modo de articulación fricativa.

En cuanto a la aproximante, al ser un sonido muy escaso en las lenguas del mundo y por su dificultad articulatoria (se debe doblar la punta de la lengua hacia atrás), provocó que algunos estudiantes decidieran usar la vibrante simple española, y en número menor, la vibrante múltiple.

Con relación a la consonante lateral no identificamos fenómenos que afectaran gravemente la lengua o el sistema, sin embargo llamamos la atención sobre la formación de consonantes silábicas que mencionamos anteriormente. Recordándolo en algunos ejemplos tenemos castle, people, apple *['kasol], *['pipol], *['apol] que se producirían /' $\mathrm{k}^{\mathrm{h}} æ \mathrm{l} \mathrm{l} / /, \mathrm{I}^{\mathrm{h}} \mathrm{i}: \mathrm{p}^{\mathrm{h}} \mathrm{l} /$, /'æp $\mathrm{p}_{\mathrm{l}}^{\mathrm{h}} /$. Allí la elisión de schwa 
origina una conversión de la consonante lateral implosiva en una consonante silábica (igual sucede con la $/ \mathrm{n} / \mathrm{y} / \mathrm{m} /$ ).

Finalmente encontramos que la nasal-velar /y/ presentó los dos fenómenos ya mencionados.

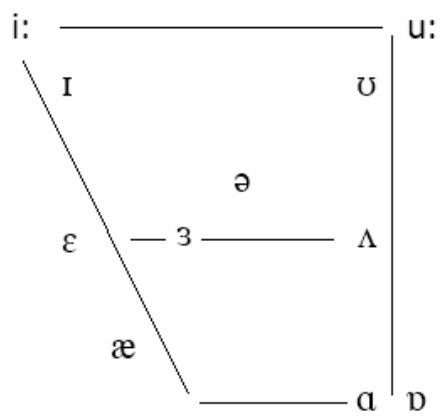

3.1.2. Vocales: Es notorio que de doce vocales que tomamos como repertorio del inglés estandarizado, nueve representaron dificultades principalmente de índole articulatoria, lo que generó errores de lengua y errores de sistema. Retomando lo expresado arriba, la problemática giró en torno a la sustitución en beneficio de los sonidos vocálicos de la LM, apoyada por la sordera fonológica que impidió distinguir sonidos similares. El ejemplo más representativo y sorprendente para nosotros como investigadores fue la multiplicidad de formas fonéticas que adquirió la vocal neutra /ə/, que encontramos como [i], [e], [a], [o], [u]. Esto muestra que la interferencia que la LM ejerce sobre ILE obliga un acercamiento al estudio fonético-fonológico de la lengua objeto y una gran capacidad de autorregulación que permita al aprendiente reconocer sus errores y buscar la forma de disminuirlos.

Otro hallazgo importante fue la duración de los elementos vocálicos de ILE. Allí, la falta de producción de sonidos largos, generada por la sordera fonológica y/o la pereza articulatoria ${ }^{6}$ originó errores graves que conllevaron por un lado, a anomalías léxicas (errores de sistema) o por el otro, a confusiones de orden semántico (errores de regla).

Desde el punto de vista articulatorio podemos mencionar afectaciones desde los tres órganos articuladores que mencionamos antes. En primer lugar está lo que

6. Para algunos autores como AGUD (2004, p. 25), la pereza articulatoria "es la tendencia a erosionar la pronunciación y a desdibujar diferencias y contrastes" lo que coincide con nuestra idea en el sentido de no aplicar ningún esfuerzo por pronunciar adecuadamente un sonido según su descripción fisio-articulatoria. 
atañe al movimiento lingual que, para el caso de español, no requiere posiciones permanentemente ubicadas hacia el centro de la cavidad oral, y sí son obligatorias en la lengua inglesa. Allí la interferencia de los movimientos adelantados o atrasados del español generó errores serios de comunicación. En segundo lugar encontramos que la apertura mandibular también afecta la producción de los sonidos del inglés que exigen una articulación mucho más abierta que la generalidad de los sonidos del español. Así la interferencia dificultó la conformación articulatoria de los sonidos e hizo que la producción de la LE se escuchara bastante bizarra. En tercer lugar, podemos mencionar, con respecto al movimiento labial, que los estudiantes mostraron una preferencia a tensionar sus labios cuando gesticulan sonidos que en la oralidad se pronuncian de manera más relajada. Señalamos a este respecto que encontramos una explicación a este tipo de producción en el hecho de que, al no ser una muestra espontánea, los estudiantes tuvieron presente que iban a ser evaluados y, queriendo hacer los sonidos lo mejor posible, asociaron esa exageración con una mejora en la producción.

\subsection{Percepción de los docentes en formación sobre sus propios errores}

Para conocer las percepciones de nuestros estudiantes sobre sus propios errores y sobre el fenómeno de la interferencia aplicamos una encuesta (ver Anexo 1) que constó de una pregunta de corte cuantitativo y tres de corte cualitativo. De ello obtuvimos los siguientes resultados.

a) Pregunta No. 1. El objetivo fue conocer si encontraron una diferencia entre el inglés y su LM con respecto a la pronunciación. Antes de este análisis asumimos como investigadores que existirían más diferencias que similitudes y que el grado de interferencia negativa sería mayor, por ende, los aprendientes tendrían más dificultades para pronunciar.

Como se puede ver en la tabla el 98,14\% de los estudiantes consideró que en efecto, sí hay diferencias entre su LM y la lengua inglesa en cuanto a la pronunciación. Solamente un 1,85\%, estimó que tales diferencias no existen. De allí entendemos que nuestros docentes en formación fueron conscientes de que ambas lenguas son disímiles en cuanto a sus sistemas fonético-fonológicos. 
Tabla 3. Relación de encuestados, porcentajes y sus respuestas a la pregunta No. 1.

\begin{tabular}{|l|l|}
\hline Sí hay diferencias & No hay diferencias \\
\hline 53 encuestados & 1 encuestado \\
\hline $98.14 \%$ & $1.85 \%$ \\
\hline
\end{tabular}

b) Pregunta No. 2. La intención apuntó a las percepciones que los aprendientes tenían conforme a la respuesta dada a la pregunta anterior. Luego del estudio contrastivo en aula de clase y del ejercicio llevado acabo, sus reflexiones apuntaron a la interferencia del sistema fonético-fonológico y gráfico de la LM, la dificultad de la LE y la falta de contacto con la LE.

Influencia de la fonología de la LM

Refiere la interferencia ocasionada por la pronunciación de la LM del aprendiz, al incidir en aquella de ILE; allí, la interlengua puede contener segmentos que pertenezcan o no a cualquiera de las lenguas intervinientes. En algunos casos los encuestados reconocieron que tienen el hábito de pronunciar en inglés de la misma manera que lo hacen en su LM, y admiten que para lograr vencer esta costumbre, deben experimentar cambios radicales en su producción oral. Ello los obligaría a abandonar su zona de comodidad y progresivamente desprenderse de este arraigo lingüístico; veamos algunas opiniones:

Aureliano: "El mal aprendizaje o la tendencia a 'españolizar' ciertos sonidos que se parecen al español porque al no ser la lengua materna, la adquisición y aprendizaje de más sonidos implica acostumbrarse a cambios estructurales".

Eréndida: "Porque tengo el español tan marcado que a pesar de saber el sonido correspondiente, se produce el que sé de español".

Florentino "Porque existen un idioma y pronunciación arraigados a lo largo del tiempo por lo tanto, el empleo de otro diferente causa confusiones y dificultades".

De igual manera los aprendientes manifestaron que las vocales de su LM ocasionaron procesos de interferencia y sustitución al momento de producir aquellas en LE. Se justificaron en el hecho de que para hablantes de español es complicado comprender auditivamente las diferencias, por muy leves que sean, y producir de manera indicada. Podemos verlo con las siguientes opiniones: 
Úrsula: "Se afectaron sobre todo las vocales, es difícil captar y producir las diferencias entre $/ æ /, / \Lambda /, / \mathrm{a} /$ ".

Remedios: "Porque se suele mezclar la pronunciación del español con la identificación de los sonidos similares a la /a/".

Maruja: "La pronunciación de las vocales del español afectó el desempeño en la grabación".

Otros estudiantes van más allá y generalizan la idea pues es más que evidente que en el proceso de aprendizaje de ILE, trataron de facilitar la pronunciación, transfiriendo-consciente o inconscientemente-, aquella de su LM. Esa imitación reiterada puede ocasionar que sonidos totalmente diferentes o inexistentes en su LM sean descuidados o ignorados al hablar inglés.

Melquíades: "Imitamos los sonidos del español. Con los sonidos desconocidos para nosotros, la pronunciación se afectó porque imitamos esos sonidos y no hacemos énfasis en los elementos desconocidos".

Llama la atención una respuesta en particular de esta categoría pues el estudiante, acudiendo a su conocimiento psico y neurolingüístico hizo alusión a fenómenos biológicos como la lateralización cerebral y la ya mencionada teoría del periodo crítico de Lenneberg (1967).

Renata: "La lateralización cerebral es una de las causas que afecta el desempeño en la grabación puesto que el cerebro está acostumbrado a una pronunciación (la del español); además ya no estamos en el periodo crítico".

Complejidad del sistema de la lengua objeto

Alude a todos aquellos errores que los estudiantes cometieron, y cuya causa principal, según su reflexión, es la complejidad misma del sistema fonético/ fonológico de la lengua inglesa. Como quiera que nos suministraron múltiples y variadas respuestas, podemos resumirlas en dos: la diferencia en número del inventario de consonantes -18 para el español y 22 para inglés, y vocales -5 para el español y 12 para el inglés; y la correspondencia grafía-fonema, mucho mayor en ILE. Entre las respuestas traemos a colación las siguientes:

Amaranta: "Porque el inglés tiene sonidos que el español no, además de la interferencia y el cambio de voz que se produce por la grabación". 
Gastón: "Porque la articulación española es demasiado diferente a la lengua elegida. El inglés tiene más cantidad de sonidos que el español y son sonidos que no estaban en nuestra mente para reproducirlos en lengua extranjera"

Nicanor: "Porque el inglés tiene más sonidos que el español en cambio éste tiene un sonido para cada letra"

Además de lo anterior, los encuestados hicieron serias reflexiones desde el punto de vista fisioarticulatorio explicando sus errores. Es el caso de Fermina quien resalta como causa principal, la posición lingual que debe adoptarse en inglés; y Arcadio especifica y menciona dos de los segmentos evidentemente más complejos desde el punto de vista articulatorio: la consonante / $\mathrm{x} / \mathrm{y}$ la vocal /æ/. Pero Amaranta es aún más pesimista al revelar una concepción no muy alentadora para los aprendientes pero sí digna de tener en cuenta: la fonética inglesa es tan compleja que solo los hablantes nativos pueden producir ciertos tipos de sonidos de manera adecuada.

Influencia de la escritura de la LM

Señala la costumbre de asociar grafemas y fonemas por lo que tendemos a pronunciar, en la mayoría de los casos, tal y como se escribe (LADO, 1958). Recalcamos, como dijimos arriba, que, contrastado con el inglés, el español es una lengua mucho más fonética (DELATTRE, 1945). Comúnmente en nuestras clases los aprendientes insisten en pedirnos reglas de pronunciación $\mathrm{y}_{\text {, de }}$ cierta manera, se frustran al escucharnos decir que la lengua inglesa se rige por excepciones y que no es recomendable asociar la ortografía con la pronunciación pues no conviene generalizar. Así, luego de ser conscientes de la no correlación grafema/fonema en ILE, los encuestados expresaron:

José Arcadio: "En el español estamos acostumbrados a como se escribe y se pronuncia y en cambio en el inglés no funciona de la misma manera".

Pilar: "Se está acostumbrado a pronunciar las palabras tal y como se ven, entonces cuando se quiere pronunciar en inglés es muy difícil producirlas correctamente ya que la escritura es muy diferente a la pronunciación".

Agustín: "Para empezar, se dificultó más por lo que en español las palabras se pronuncian como están escritas, en cambio en el inglés, la escritura es muy diferente a como se pronuncian muchos sonidos". 
Inhabilidad para reconocer la pronunciación de vocales y consonantes Apunta a la sordera fonológica o la inhabilidad para reconocer auditivamente los sonidos distintos en LM y LE, y para discriminar sonidos que en esa LE son similares (POLIVANOV, 1931). La relevancia está en la conexión entre las habilidades de escucha y las de habla. Las respuestas que citamos describen claramente el impacto de no poder escuchar bien y por ello, de no poder producir oralmente de manera apropiada:

Sabas: "...porque me faltaba reconocer los sonidos exactos de cada vocal o consonante".

Isabel: "Porque a la hora de producir los sonidos se tiende a reproducirlos en la lengua materna tal vez por mala costumbre o por dificultad en la diferenciación de la producción."

Meme: "Por las diferentes vocales y la distinta manera como suenan".

Falta de inmersión lingüística.

Sugiere la posibilidad que tiene un aprendiz para hablar la LE en contextos diferentes al de aprendizaje y con personas nativas o cuasi nativas que la empleen no como fin sino como vehículo de comunicación. Este método de aprendizaje es el que Cloud et al. (2000) denominan inmersión total. A través de él, la lengua que se aprende se emplea en el $100 \%$ de los contextos y no debe ser el objeto de estudio sino un medio para adquirir conceptos sobre otras asignaturas, sobre el mundo y sobre otras culturas. Nuestros docentes de formación dejan ver la necesidad de practicar y emplear la lengua inglesa en diversos escenarios para así poder pronunciar de forma menos artificial y más natural. Los siguientes ejemplos dan cuenta de esta falencia:

Martín: "Porque su producción no está naturalizada en nuestra lengua".

Bayardo: "Porque no estamos acostumbrados a escuchar esos sonidos y por eso se nos hace difícil pronunciarlos".

Victoria: "Al no conocer bien la pronunciación y al no estar familiarizada con el idioma en cuanto a su fonética se pudo ver distorsionada la vocal o consonante por lo tanto o cambió el significado o se pronunció mal".

c) Pregunta No. 3. La intención fue conocer las causas que los encuestados estiman que afectaron su producción oral en lengua inglesa. Al analizar las múltiples respuestas, emergieron las siguientes categorías principales: 
Dificultad para pronunciar y articular

Apunta a las dificultades que experimentaron nuestros estudiantes al tratar de producir, articular o imitar los sonidos consonánticos y vocálicos propios de la lengua inglesa. Esta situación se origina en la complejidad del nuevo sistema fonético-fonológico, marcada por la divergencia con el de su LM. La dificultad de pronunciar y articular de manera apropiada se derivó directamente de la sordera fonológica, la dificultad misma que ofrecen los sonidos, la inhabilidad

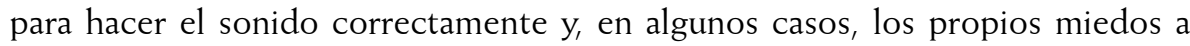
cometer errores y a arriesgar (TORRES, 2005) -lo que tiene su origen en el ego lingüístico (BROWN, 2007). Todo lo anterior hace que nuestros aprendientes luzcan frágiles, estén a la defensiva con respecto a los errores y se inhiban. Estas son algunas de sus percepciones:

María Alejandrina: "Pienso que produje esos errores por la diferencia de pronunciación entre español e inglés, y no es fácil identificar y articular las diferencias".

Houdini: "Porque se me dificulta realizar las fricativas sonoras, en el segundo caso porque realmente no entiendo la diferencia entre los dos sonidos y en el otro porque es un sonido que no puedo hacer por mucha práctica que haga".

Pablo: "ær/ se me dificulta porque al concentrarme en las consonantes la decía como /a/i / $/$ la confundí con/f/ por su similitud, /ə/ la confundí porque es un sonido difícil, / $/$ / lo dije /æ/ por nervios".

\section{Sordera fonológica}

Alude al fenómeno que ayuda a explicar algunos de los problemas que nuestros estudiantes tienen en relación con su percepción de la LE. Aquí se genera claramente una interferencia (POLIVANOV, 1931) pues, al no distinguir claramente los rasgos diferenciales de dos fonemas el hablante se ve obligado a pronunciarlos mal y la oralidad se escucha entonces, con marcado acento extranjero. Para evitarlo, nuestros estudiantes deberán hacer ejercicios de escucha y producción guiados so pena de producirlos mal hasta el final de su carrera y emplearlos así en su vida profesional. Al respecto traemos algunas de sus percepciones:

Lázaro: "Posiblemente porque mi producción fónica está condicionada por mi memoria auditiva". 
Cristóbal: "sentía los sonidos del inglés se parecían mucho a mi pronunciación en español y los hacía como los escuchaba".

Clotilde: "Porque los sonidos en inglés son similares y no los distingo".

Poca autorregulación

Apunta al propio uso del tiempo, del esfuerzo y de la debida atención que los estudiantes le brindan a la LE, lo que se refleja en la búsqueda de estrategias individualizadas para comprender y producir (BROWN, 2001). Es valioso encontrar que un número importante de estudiantes como los que mencionamos a continuación reconocen que sus errores fonéticos fueron producidos precisamente por su falta compromiso y autonomía y no por la influencia de la LM, la LE o agentes externos:

Rogelio: "Hubo falta de conciencia de mi parte y falta de autoevaluación de mi producción".

Hortensia: "Cometí varios errores por falta de práctica".

Cristo: "porque no practiqué lo suficiente y... lo hice de afán".

Petronio: "no seguí recomendaciones y hubo sonidos que no practiqué".

$\sim$ Por influencia de la LM

Recalca, como se indicó arriba, el papel de la LM al momento de buscar posibles explicaciones para sus errores fonéticos y fonológicos. A nuestro juicio esto va en consonancia con el hecho de que casi unánimemente coincidieron en que el sistema fonético-fonológico del español es muy diferente al del inglés y por esas divergencias es obvio para ellos que la lengua que usan cotidianamente prime e incida en la manera en que producen oralmente. Según los estudiantes, esta influencia no se vislumbra solamente en los aspectos segmentales sino también en los suprasegmentales, y por eso adoptan el marcado y ya referenciado acento extranjero. Algunos de los argumentos esgrimidos son:

Alberta: "porque la pronunciación del español, está muy marcada en inglés".

Margot: "porque estoy muy familiarizada con el español".

Flora: "porque imito mi acento nativo al bablar inglés". 


\section{CONCLUSIONES Y RECOMENDACIONES}

Luego del análisis de los errores que presentó nuestra muestra de estudiantes hispanófonos en la producción de consonantes y vocales es central recalcar algunos hallazgos interesantes y ciertas falencias desde su papel como aprendices y desde su rol como futuros docentes de ILE.

Entre los hallazgos encontramos una interlengua en proceso que se evidenció en las sustituciones tanto consonánticas como vocálicas, siendo menos problemáticas las primeras por el menor número de oposiciones existentes entre ILE y el español. En cuanto a las vocales, fue notorio que por su amplio repertorio en el inventario fonológico de la LE, la cantidad de errores en su proceso de interlengua fue mayor, lo que requerirá asimismo una mayor inversión estratégica.

Estamos convencidos que a base de una práctica consciente y un ejercicio analítico los aprendices de ILE pueden superar muchos de los errores de pronunciación que hemos referido. Es claro que la pronunciación adecuada no llega de manera espontánea y natural en contextos de aprendizaje sino como resultado de un esfuerzo por repetir, corregir, incorporar realimentación del docente e imitar constantemente aquel acento que se desea tener. Si los aprendientes no "invierten" en su aprendizaje, muy difícilmente obtendrán esos resultados inmediatos que persiguen. Esta labor exige a ir más allá de los espacios académicos que provee la institución y exhorta a sumergirse en entornos de inmersión lingüística o a aprovechar medios técnicos y tecnológicos, que no solo faciliten la práctica oral sino que provean información lingüística real que disminuya las limitaciones que la LM les impone.

De otro lado, el ejercicio metacognitivo llevado a cabo durante el semestre y en el tiempo que duró la investigación generó una conciencia de parte de los docentes en formación sobre la diferencia entre las dos lenguas que se abordaron, forjando un proceso de reflexión constante sobre la propia práctica, y de proyección hacia un ejercicio que apunte a aminorar el impacto de la criba fonológica. Precisamente relacionado con esto último, el reconocimiento de la interferencia de la LM hizo que los aprendientes se concientizaran del nivel de dificultad que genera la LE, y en esa misma medida, el contraste los conminara a buscar sus propias estrategias para eliminar sus errores.

Es relevante señalar que solo la ejercitación continua y permanente lleva a disminuir la dificultad articulatoria de los sonidos de ILE. A los profesores de lengua extranjera, le reiteramos algunos de los ya nombrados ejercicios: a) la gesticulación exagerada (a diversas velocidades), que debe ir ligada a un proceso de auto grabación, observación y escucha junto con imitación; b) La repetición 
de trabalenguas que contengan sonidos consonánticos y vocálicos y que apunten a un objetivo lingüístico concreto; c) la eliminación de la influencia de la escritura al evitar la generalización de reglas y más bien propender por la búsqueda de excepciones; y d) el uso de la transcripción como ejercicio complementario para eliminar errores de producción oral.

Solo una práctica consciente, juiciosa y reiterada de parte del aprendiz, junto con un acompañamiento dedicado y específicamente orientado de parte del docente, pueden contribuir a mejoras notorias en el ejercicio de la pronunciación en ILE.

\section{BIBLIOGRAFÍA}

AGUD, A. (2014). La cientificidad en la lingüística y el papel histórico en la lingüística europea: alegato para tiempos difíciles. In: Faventia. v. 34, pp. 15-30. Disponible en: $<$ http://www.raco.cat/index.php/Faventia/article/view/320878/411362>. Acceso el: 13 ago. 2017

BAYRAKTAROĞLU, S. (2008). Orthographic interference and the teaching of British pronunciation to Turkish learners. In: Journal of Language and Linguistic Studies. v. $4, \mathrm{n}^{\circ}$ 2. Disponible en: <http://www.jlls.org/index.php/jlls/article/view/67/67>. Acceso el: 9 ago. 2017.

BARTOLÍ, M. (2005). La pronunciación en la clase de lenguas extranjeras. In: Phonica. $\mathrm{n}^{\mathrm{o}}$ 1, pp. 1-27. Barcelona. Universidad de Barcelona. Disponible en: <http://www. publicacions.ub.edu/revistes/phonica1/PDF/articulo_02.pdf>. Acceso el: 19 abr 2017

BIN-HADY, W. (2016). Teaching Pronunciation for Arab learners of English: Using Gilberts' Prosody Pyramid. In: South -Asian Journal of Multidisciplinary Studies. v. 3, p. 138-151. Disponible en: < https://www.researchgate.net/publication/301778636_ Teaching_Pronunciation_for_Arab_learners_of_English_Using_Gilberts' Prosody_Pyramid>. Acceso el: 8 ago. 2017.

BRIZ, I. (2011). ¿Por qué enseñar pronunciación? Análisis y propuesta didáctica. In: IV Jornadas de formación de profesores de español como lengua extranjera en China. Suplementos SinoELE. no 5. Pekín, 24-26 de junio de 2011 Disponible en: <www. sinoele.org/images/Congresos/IVJornadas/Actas/briz_155-173.pdf> . Acceso el: 19 abr 2017 
BROWN, H. D. (2007) Principles of language learning and teaching. $5^{\text {th }}$ ed. White Plains: Pearson

BROWN, H. D. (2001) Teaching by principles: An Interactive Approach to Language Pedagogy. $2^{\text {nd }}$ ed. New York: Longman

BURKHARDT, E. (2004). Le traitement de l'erreur de production orale en classe hétérogène plurilingue. Lyon: Université Lumière Lyon 2. Disponible en: $<$ http:// theses.univ-lyon2.fr/documents/lyon2/2004/burkhardt_e>. Acceso el: 19 abr 2017

CALVO, Y. (2013). La enseñanza de la pronunciación del inglés en Galicia: una asignatura pendiente. In: Actas del XLI Simposio Internacional de la Sociedad Española de Lingüística (SEL). CABEDO, A.; AGUILAR, M.; LÓPEZ-NAVARRO, E. (Eds.), Estudios de lingüística: investigaciones, propuestas y aplicaciones (2013). Universidad de Valencia, pp. 13-20. Disponible en: <http:/www.uv.es/canea/ archivos/Estudios_linguistica_2013.pdf>. Acceso el: 9 ago. 2017.

CANALE, G. (2012). La adquisición de /v/ en la interfonología español-inglés: un estudio sociolingüístico de estudiantes montevideanos. In: Estudios de lingüística inglesa aplicada. $\mathrm{n}^{\mathrm{o}} 12$, p. 153-180. Disponible en: < http://institucional.us.es/revistas/ elia/12/art_6.pdf>. Acceso el: 10 ago. 2017.

CATALÁN, C. (2017). Problems when teaching Pronunciation in an "English as a second language" classroom. In: Publicaciones didácticas. no 80. P. 780-783. Disponible en: $<$ http://publicacionesdidacticas.com/hemeroteca/articulo/080129/articulo-pdf $>$. Acceso el: 9 ago. 2017.

CELCE-MURCIA, M; BRINTON, D; GOODWIN, J. (1996). Teaching pronunciation: a Reference for Teachers of English to Speakers of Other Languages. New York: Cambridge University Press. DOI: 10.2307/3588013

CHOMSKY, N. (1965/1999). Aspectos de la teoría de la sintaxis. Barcelona, Gedisa

CHOMSKY, N. (1968/1977). El lenguaje y el entendimiento. Barcelona, Seix-Barral

CLOUD, N.; GENESEE, F.; HAMAYAN, E. (2000). Dual Language Instruction: a Handbook for Enriched Education. Boston: Heinle and Heinle.

CORDER, S. P. (1967). The Significance of Learners' Errors. International Review of Applied Linguistics in Language Teaching, $n^{\circ}$ 5, 161-170. DOI: https://doi. org/10.1515/iral.1967.5.1-4.161. 
FREEMAN, D. (1998). Doing teacher research: From inquiry to understanding. San Francisco: Heinle \& Heinle.

FRIES, CH. (1945). Teaching and learning English as a foreign language. In: Publications of the English Language Institute. $n^{\circ} 1$. Ann Arbor: University of Michigan Press

GRICE, P. (1975). Lógica y Conversación. In: Valdés V., L. M. (ed.) (1991). La búsqueda del significado: Lecturas de filosofía del lenguaje. Madrid: Tecnos. 511-530. Disponible en: <https://es.scribd.com/doc/141201668/Luis-M-Valdes-Villanuevaed-La-busqueda-del-significado-1991>. Acceso el: 18 mar 2017

GUZMÁN, E.; MARTÍNEZ, C. (2013). Interferencia fonética del español al inglés en la producción de los fonemas $/ b / / v /, / \theta / / t /, / 3 / / d z /$, $/ \int / / t /$. Trabajo de grado de la Licenciatura en lenguas modernas. Pontificia Universidad Javeriana, Bogotá. Disponible en: $<$ https://repository.javeriana.edu.co:8443/bitstream/handle/10554/17088/ GuzmanMunozElianaPaola2014.pdf? sequence $=1$ \&isAllowed $=y>$. Acceso el: 10 ago. 2017 .

LADO, R. (1958). Linguistics across cultures: Applied Linguistics for Language Teachers. Ann Arbor: The University of Michigan Press

MARTÍN, M. A. (2009). Historia de la metodología de enseñanza de lenguas extranjeras. In: Tejuelo. Revista de didáctica de la lengua y la literatura. ${ }^{0}$ 5, p. 54-70. Disponible en: <https://dialnet.unirioja.es/descarga/articulo/2983568.pdf>. Acceso el: 18 mar. 2017.

DE EUROPA, C. (2002). Marco común europeo de referencia para las lenguas. Estrasburgo: Consejo de Europa, Ministerio de Educación, Cultura y Deporte/Instituto Cervantes. Disponible en: < http://cvc.cervantes.es/ensenanza/biblioteca_ele/marco/cvc_mer. pdf $>$. Acceso el: 25 mar 2017

DELATTRE, P. (1945) Spanish is a phonetic language. In: Hispania. v. 28, no 4, pp. 511 516. DOI: $10.2307 / 333798$

KRASHEN, S. (1982/2009) Principles and Practice in Second Language Acquisition. University of Southern California. Disponible en: <http://www.sdkrashen.com/ content/books/principles_and_practice.pdf>. Acceso el: 18 mar 2017.

LEE, K. (2012). L'interprétation des erreurs du français chez des apprenants coréens. In: Informe de investigación de Educación del Lenguaje basado en el corpus. n⿳0 9, pp. 11-19. Seúl: Université Sang-Myung. Disponible en: < http://cblle.tufs.ac.jp/assets/ 
files/publications/working_papers_09/section/011-019.pdf $>$. Acceso el : 19 abr 2017

LENNEBERG. E.H. (1967). Biological foundations of language. New York: Wiley.

LLISTERRI, J. (2003). La enseñanza de la pronunciación. Cervantes: Revista del Instituto Cervantes en Italia, $n^{\circ}$ 4, pp. 91-114. Disponible en: < http://liceu.uab.es/ joaquim/ publicacions/Llisterri_03_Pronunciacion_ELE.pdf $>$. Acceso el: 26 mar 2017

LLEÓ, C. (1997). La adquisición de la fonología de la primera lengua y de las lenguas extranjeras. Madrid: Visor

POLIVANOV, E. (1931). La perception des sons d'une langue étrangère. In: Travaux du Cercle de Linguistique de Prague. no 4, pp. 79-96.

OHATA, K. (2004). Phonological Differences between Japanese and English: Several Potentially Problematic Areas of Pronunciation for Japanese ESL/EFL Learners. In: The Asian ELF Journal. Indiana: Indiana University of Pennsylvania. Disponible en: <http://www.asian-efl-journal.com/Dec_04_ko.pdf>. Acceso el: 8 ago. 2017.

ORDUZ, Y. (2012). La transferencia de la fonología de la lengua materna en la adquisición del inglés como lengua extranjera. In: Entornos. $n^{0} 25$, pp. 91-103. Neiva, Universidad Surcolombiana. Disponible en: <https://www.journalusco.edu.co/ index.php/entornos/article/view/429/802 >. Acceso el: 25 mar 2017

QUILIS, A. (1993). Tratado de fonología y fonética españolas. Madrid: Gredos

SANTOS GARGALLO, I. (1993). Análisis contrastivo, análisis de errores e interlengua en el marco de la lingüística contrastiva. Madrid: Síntesis.

SELINKER, L. (1969). Language transfer. In: General Linguistics. nº 9, pp. 67-92.

SPERBER, D.; WILSON, D. (1986). Relevance: Communication and Cognition. Oxford: Blackwell.

TORRES, J. R. (2005) El mito del período crítico para el aprendizaje de la pronunciación de un idioma extranjero. In: Pnonica. v. 1, pp. 1-9. Disponible en: <www.publicacions. ub.edu/revistes/phonica1/PDF/articulo_06.pdf>. Acceso el: 25 mar 2017

TROUBETZKOY, N. S. (1973/1987): Principios de fonología, Madrid: Cincel. 
USÓ, L. (2008). La enseñanza de la pronunciación en LE: Algunas consideraciones a tener en cuenta. In: Phonica. $\mathrm{n}^{\circ}$ 4, pp. 104-130. Barcelona. Universidad de Barcelona. Disponible en: < http://www.publicacions.ub.edu/revistes/phonica4/ documentos/580.pdf> . Acceso el: 19 abr 2017

VIOQUE, S. (2015). Análisis de la influencia de una primera y segunda lengua en la adquisición de la fonología de una tercera: un estudio comparativo de las consonantes oclusivas y africadas del español, inglés y alemán. Tesis de doctorado en Lenguas y culturas. Disponible en: $<$ http://helvia. uco.es/xmlui/bitstream/handle/10396/13316/2016000001360.pdf? sequence $=1>$. Acceso el: 8 ago. 2017.

WANG, X. (2009). Exploring the Native Transfer on English Learning. In: Asian Social Science. v. 5, $\mathrm{n}^{\mathrm{o}} 7$, pp. 138-143. Disponible en: <http://www.ccsenet.org/journal/ index.php/ass/article/viewFile/2981/2748>. Acceso el: 25 mar 2017.

WHEELOCK, A. (2016). Phonological difficulties encountered by Italian learners of English: An error analysis. In: TESOL Working Paper Series. Honolulu: Hawaii Pacific University. v. 14, p. 41-61. Disponible en: < https://docs.google.com/ viewerng/viewer?url=http://asian-efl-journal.com/Dec_04_ko.pdf\&hl=en_US $>$. Acceso el: 8 ago. 2017 


\section{ANEXO 1. DOS EJEMPLOS DE RESPUESTAS DADAS A LA PRIMERA ENCUESTA APLICADA}

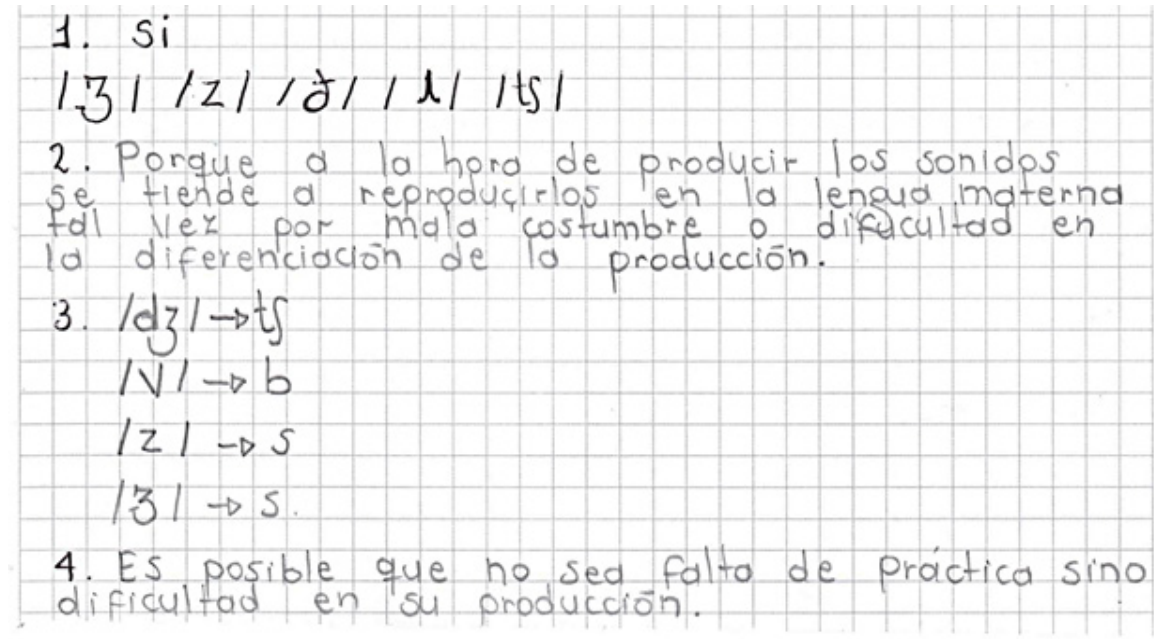

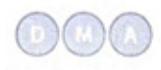

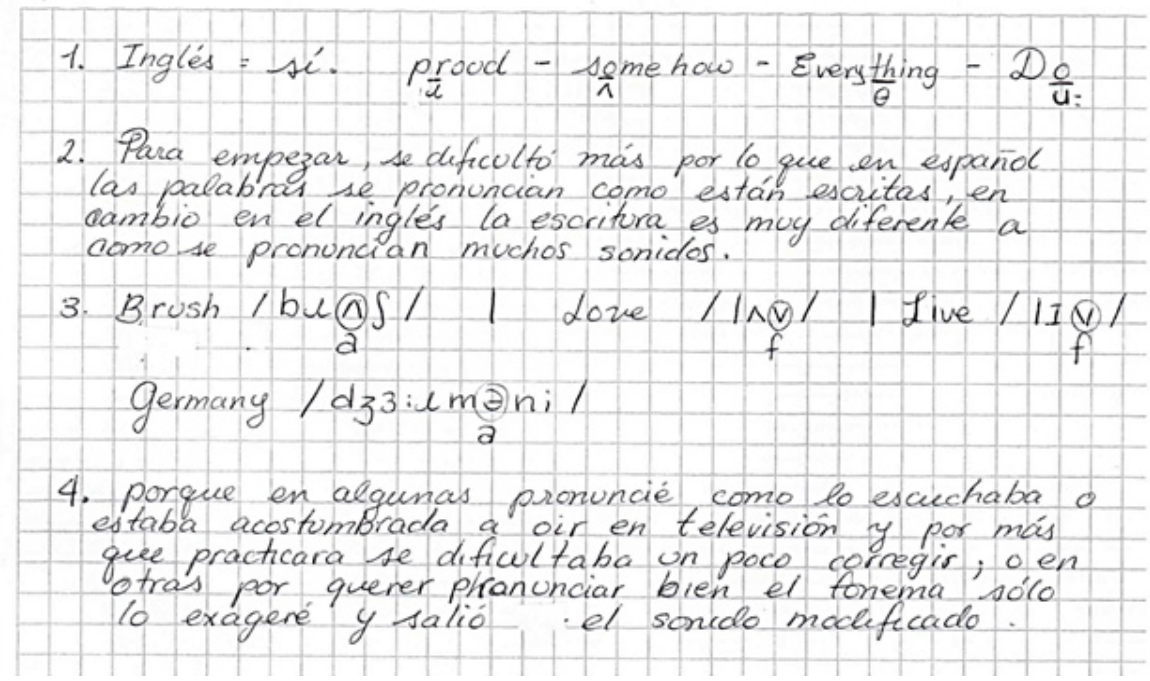

Recebido: 15/08/2017

Aceito: 18/07/2018 